\title{
AMD3100 and SDF-1 regulate cellular functions of endothelial progenitor cells and accelerate endothelial regeneration in a rat carotid artery injury model
}

\author{
CHUNYU JIANG $^{1 *}$, RUITING LI ${ }^{1 *}, \mathrm{XU} \mathrm{MA}^{1}, \mathrm{HUI} \mathrm{HU}^{1}, \mathrm{JUAN} \mathrm{GUO}^{2}$ and JUNGONG ZHAO ${ }^{1}$ \\ Departments of ${ }^{1}$ Radiology and ${ }^{2}$ Hematology, The Sixth People's Hospital, Affiliated \\ to Shanghai Jiao Tong University, Shanghai 200233, P.R. China
}

Received January 9, 2020; Accepted June 22, 2020

DOI: $10.3892 / \mathrm{mmr} .2020 .11432$

\begin{abstract}
The present study was conducted to assess the effects of AMD3100 and stromal cell-derived factor 1 (SDF-1) on cellular functions and endothelial regeneration of endothelial progenitor cells (EPCs). The cell proliferation and adhesion capacity of EPCs were evaluated in vitro following treatment with AMD3100 and SDF-1 using a Cell Counting Kit-8 assay. Furthermore, the expression levels of $\mathrm{C}-\mathrm{X}-\mathrm{C}$ motif chemokine receptor 4 (CXCR4) and $\mathrm{C}-\mathrm{X}-\mathrm{C}$ motif chemokine receptor 7 (CXCR7) were detected before and after treatment with AMD3100 and SDF-1 to elucidate their possible role in regulating the cellular function of EPCs. A rat carotid artery injury model was established to assess the influences of AMD3100 and SDF-1 on endothelial regeneration. AMD3100 reduced the proliferation and adhesion capacity of EPCs to fibronectin (FN), whereas it increased the adhesion capacity of EPCs to human umbilical vein endothelial cells (HUVECs). However, SDF-1 stimulated the proliferation and cell adhesion capacity of EPCs to HUVECs and FN. Additionally, the expression levels of CXCR7 but not CXCR4 were upregulated following AMD3100 treatment, whereas the expression levels of both CXCR4 and CXCR7 were upregulated after SDF-1 treatment. In vivo results demonstrated that AMD3100 increased the number of EPCs in the peripheral blood and facilitated endothelial repair at 7 days after treatment. However, local administration of SDF-1 alone did not enhance reendothelialization 7 and 14 days after
\end{abstract}

Correspondence to: Dr Jungong Zhao, Department of Radiology, The Sixth People's Hospital, Affiliated to Shanghai Jiao Tong University, 600 Yi-Shan Road, Shanghai 200233, P.R. China

E-mail: zhaojungongradio@hotmail.com; zhaojungong@sjtu.edu.cn

*Contributed equally

Key words: endothelial progenitor cells, reendothelialization, $\mathrm{C}-\mathrm{X}-\mathrm{C}$ motif chemokine ligand 12, C-X-C motif chemokine receptor 4, C-X-C motif chemokine receptor 7, adhesion capacity, neointimal hyperplasia treatment. Importantly, the combination of AMD3100 with SDF-1 exhibited superior therapeutic effects compared with AMD3100 treatment alone, accelerated reendothelialization 7 days after treatment, and attenuated neointimal hyperplasia at day 7 and 14 by recruiting more EPCs to the injury site. In conclusion, AMD3100 could positively regulate the adhesion capacity of EPCs to HUVECs via elevation of the expression levels of CXCR7 but not CXCR4, whereas SDF-1 could stimulate the proliferation and adhesion capacity of EPCs to FN and HUVECs by elevating the expression levels of CXCR4 and CXCR7. AMD3100 combined with SDF-1 outperformed AMD3100 alone, promoted early reendothelialization and inhibited neointimal hyperplasia, indicating that early reendothelialization attenuated neointimal hypoplasia following endothelial injury.

\section{Introduction}

In-stent restenosis (ISR) after stent implantation remains a serious clinical challenge, and $\sim 26.4 \%$ of patients experience ISR after implantation of stents (1). New-generation drug-eluting stents have reduced the incidence of ISR to $10 \%$ (2-4); however, local anti-proliferative therapy may interfere with vascular healing, and incomplete neointimal coverage 3-6 months after stent implantation has been identified to be associated with late stent thrombosis (5). Previous studies have demonstrated that early reendothelialization can reduce vascular neointimal hyperplasia and restenosis, indicating that endothelial regeneration is essential to prevent unfavorable vascular events $(6,7)$. Endothelial progenitor cells (EPCs) can accelerate reendothelialization and attenuate neointimal hyperplasia $(8,9)$. However, the concentration of circulating EPCs may be decreased in patients with risk factors for heart disease, including elevated low-density lipoprotein (LDL) cholesterol, diabetes mellitus and hypertension (10-12). The aforementioned data indicate that it is crucial for endothelial regeneration to mobilize more circulating EPCs to enhance early reendothelialization.

AMD3100, also known as plerixafor, an antagonist of C-X-C motif chemokine receptor (CXCR)4, has been proposed, instead of granulocyte colony-stimulating factor, to mobilize $\mathrm{CD} 34^{+}$hematopoietic stem or progenitor cells (HSCs) derived from bone marrow $(13,14)$. The underlying mechanism of 
AMD3100 mobilization of progenitor cells involves interfering with the stromal cell-derived factor 1 [SDF-1, also known as C-X-C motif chemokine ligand (CXCL)12]/CXCR4 signaling pathway, which is vital for the retention of EPCs in niches, and then forcing the release of circulating EPCs (15). The process of EPC homing, including mobilization, recruitment and adhesion, is regulated by key angiogenic chemokines (CXCL1, CXCL7, CXCL12 and C-C motif chemokine ligand 2) and their respective receptors (CXCR2, CXCR4 and $\mathrm{C}-\mathrm{C}$ motif chemokine receptor 2). Previous studies have reported that the homing or recruitment of circulating EPCs to injury or ischemic sites by SDF-1 is an important process for executing their angiogenic and repair functions (16-18). These results indicate that AMD3100 and SDF-1 may be useful for endothelial regeneration. Therefore, the present study evaluated the effects of AMD3100 and SDF-1 on endothelial repair in a rat carotid artery injury model. Furthermore, the influence of AMD3100 and SDF-1 on the cellular function of EPCs and the expression levels of CXCR4 and CXCR7 in EPCs after treatment with AMD3100 and SDF-1 was assessed.

\section{Materials and methods}

Isolation, cultivation and identification of EPCs. A total of $20 \mathrm{ml}$ fresh human umbilical cord blood was obtained from the Obstetrics Department of Shanghai Sixth People's Hospital (Shanghai) and all participants (totally 20 patients; mean age: 24 years old) provided written informed consent. EPCs were isolated from the human umbilical cord blood by Ficoll gradient centrifugation $(1,500 \mathrm{x} \mathrm{g})$ for $10 \mathrm{~min}$ at room temperature and cultured in endothelial basal medium (Lonza Group Ltd.) containing growth factors (hydrocortisone, $0.2 \mathrm{ml}$; human basic fibroblast growth factor-B, $2 \mathrm{ml}$; vascular endothelial growth factor, $0.5 \mathrm{ml}$; Recombinant human R3 insulin-like growth factor-1, $0.5 \mathrm{ml}$; human epidermal growth factor, $0.5 \mathrm{ml}$; ascorbic acid, $0.5 \mathrm{ml}$; and gentamicin sulfate-amphotericin, $0.5 \mathrm{ml}$ ). Isolation, cultivation and identification of EPCs were performed as described previously (6). Fluorescent staining was used to detect the uptake of Dil-ac-LDL (Molecular Probes; Thermo Fisher Scientific, Inc.) and binding of FITC-UEA-l (Sigma-Aldrich; Merck KGaA). Briefly, the cells were incubated with Dil-ac-LDL $(15 \mu \mathrm{g} / \mathrm{ml})$ for $4 \mathrm{~h}$, and then stained with FITC-UEA-l $(10 \mu \mathrm{g} / \mathrm{ml})$ for $1 \mathrm{~h}$ and with DAPI for $5 \mathrm{~min}$ at room temperature. The cells were washed three times and analyzed under a fluorescence microscope (Olympus Corporation). EPCs at passages 2-4 were used in subsequent experiments.

Proliferation assay of EPCs. The proliferation assay of EPCs was performed to construct a cell proliferation curve after treatment with AMD3100 and SDF-1. Briefly, EPCs were seeded into 96 -well plates at a density of $1 \times 10^{4}$ cells/well (Corning Life Sciences) and cultured in $100 \mu 1$ microvascular endothelial cell growth medium-2 (Lonza Group Ltd.) supplemented with 5\% FBS (Gibco; Thermo Fisher Scientific, Inc.) for $24 \mathrm{~h}$ at $37^{\circ} \mathrm{C}$. Subsequently, the EPCs were incubated with AMD3100 (MedChemExpress) at different concentrations $(10,1,0.1,0.01$ and $0.001 \mu \mathrm{M})$ or SDF-1 $\alpha$ (Cedarlane) at various concentrations $(1,000,100,10,1$ and $0.1 \mathrm{nM})$ for $6,12,24$ and $48 \mathrm{~h}$ at $37^{\circ} \mathrm{C}$. Then, cells were incubated with Cell
Counting Kit-8 solution (Dojindo Molecular Technologies, Inc.) for $2 \mathrm{~h}$ according to the manufacturers' protocols. Saline was used instead of AMD3100 or SDF-1 in the control group. The absorbance was measured at $450 \mathrm{~nm}$ in each well using a Synergy Multi-Mode Microplate Reader (BioTek Instruments, Inc.). The $50 \%$ effective concentration $\left(\mathrm{EC}_{50}\right)$ of $\mathrm{AMD} 3100$ and SDF-1 was calculated for subsequent experiments based on the proliferative activity at different concentrations following incubation for $24 \mathrm{~h}$. The $\mathrm{EC}_{50}$ value was calculated using GraphPad software (GraphPad Prism 7.00; GraphPad Software, Inc.).

Adhesion assay. The adhesion ability of EPCs to fibronectin (FN; Sigma-Aldrich; Merck KGaA) and human umbilical vein endothelial cells (HUVECs; Yuchi (Shanghai) Biotechnology Co., Ltd.) was assessed by plating EPCs into 24-well plates. Briefly, to investigate the adhesion of EPCs to the extracellular matrix, 24-well plates were pretreated with FN $(100 \mu \mathrm{g} / \mathrm{ml})$ for $2 \mathrm{~h}$ at $37^{\circ} \mathrm{C}$. Then, EPCs $\left(1 \times 10^{5}\right.$ cells/well $)$ were added into each well and cultured in microvascular endothelial cell growth medium-2 (Lonza Group, Ltd.) supplemented with AMD3100 (34 nM; group A), SDF-1 (212 nM; group S) or AMD3100 combined with SDF-1 (group AS) for $1 \mathrm{~h}$ at $37^{\circ} \mathrm{C}$. Unattached cells were washed away three times with PBS. DAPI $(10 \mu \mathrm{g} / \mathrm{ml})$ was used to stain the adherent EPCs for $10 \mathrm{~min}$ at $37^{\circ} \mathrm{C}$. Adherent EPCs were counted in five randomly selected fields under a fluorescence microscope (magnification, x400; Olympus Corporation).

To assess the adhesion of EPCs to HUVECs, HUVECs ( $1 \times 10^{6}$ cells/well) were seeded into 24 -well plates to form a monolayer overnight. Unattached cells were washed away using PBS. EPCs $\left(1 \times 10^{6}\right.$ cells/well) were cultured in microvascular endothelial cell growth medium-2 (Lonza Group, Ltd.) containing DiI stain $(4 \mathrm{mg} / \mathrm{ml})$ for $30 \mathrm{~min}$ at $37^{\circ} \mathrm{C}$, according to the manufacturer's protocol. DiI-labeled EPCs were digested and harvested after washing with PBS three times. Subsequently, DiI-labeled EPCs $\left(1 \times 10^{5}\right.$ cells/well) were seeded into each well and cultured in medium supplemented with AMD3100 (34 nM), SDF-1 (212 nM) or AMD3100 combined with SDF-1 at $37^{\circ} \mathrm{C}$ for $2 \mathrm{~h}$. Unattached cells were washed away three times with PBS. DAPI $(10 \mu \mathrm{g} / \mathrm{ml})$ was used to stain the HUVECs for $10 \mathrm{~min}$ at $37^{\circ} \mathrm{C}$. Adherent EPCs were counted in five randomly selected fields under a fluorescence microscope (magnification, $\mathrm{x} 400$; Olympus Corporation).

Confocal immunofluorescence microscopy. CXCR4 and CXCR7 are ligand receptors for SDF-1 and have a role in regulating the biological activities of EPCs. Therefore, the expression levels of CXCR4 and CXCR7 were assessed in each group.

Confocal immunofluorescence microscopy was performed to determine the expression levels of CXCR4 and CXCR7 in EPCs. Briefly, EPCs $\left(1 \times 10^{5}\right.$ cells/well) were grown on glass coverslips for $12 \mathrm{~h}$, fixed with $4 \%$ paraformaldehyde at room temperature for $30 \mathrm{~min}$ and incubated with $0.5 \%$ Triton X-100 (Sigma-Aldrich; Merck KGaA) for 5 min and 1\% BSA (Sigma-Aldrich; Merck KGaA) for $30 \mathrm{~min}$ at room temperature. Subsequently, EPCs were incubated with anti-human CXCR4 (1:1,000; Abcam; ab197203) and anti-human CXCR7 monoclonal antibodies (1:1,000; Abcam; ab72100) overnight 
at $4^{\circ} \mathrm{C}$, and then incubated with Alexa Fluor 488-(1:500; Abcam; ab150077) and Alexa Fluor 647-conjugated secondary antibodies (1:500; Abcam; ab150079) for $2 \mathrm{~h}$ at room temperature. Cell nuclei were stained with DAPI for $10 \mathrm{~min}$ at room temperature. Confocal immunofluorescence microscopy images were captured using a Leica TCS SP8 confocal microscope (Leica Microsystems GmbH).

Western blot analysis. Western blotting was performed to investigate the effects of AMD3100 and SDF-1 on the expression levels of CXCR4 and CXCR7 in EPCs. Briefly, EPCs $\left(1 \times 10^{6}\right.$ cells/well) were incubated with AMD3100 (34 nM), SDF-1 (212 nM) or AMD3100 combined with SDF-1 for $2 \mathrm{~h}$ at room temperature prior to protein extraction. Saline was used instead of AMD3100 or SDF-1 in the control group. Total protein was extracted using a protein extraction kit (Beijing Solarbio Science \& Technology Co., Ltd.) and quantified using a bicinchoninic acid protein assay kit (Beijing Solarbio Science \& Technology Co., Ltd.). Extracts (50 ng per lane) were subjected to $10 \%$ SDS-PAGE (Nanjing KeyGen Biotech Co., Ltd.) and then transferred onto PVDF membranes (Roche Diagnostics) before blocking with 5\% skimmed milk for $1 \mathrm{~h}$ at room temperature. The membranes were incubated with diluted primary antibodies overnight at $4^{\circ} \mathrm{C}$. The following antibodies were used: Rabbit anti-CXCR7 antibody (1:250; Abcam; ab72100), rabbit anti-CXCR4 antibody $(1: 150$; Abcam; ab197203) and rabbit anti-GADPH antibody (1:3,000; Cell Signaling Technology, Inc; 97166). Subsequently, the membranes were incubated with secondary antibody $(1: 1,000$; Beijing Boaosen Biotechnology Co., Ltd.; bs-0295D) for $2 \mathrm{~h}$ at room temperature. Protein bands were visualized using an Epson photo 1650 (Seiko Epson Corporation). Immunodetection was performed using the Supersignal West Femto Maximum Sensitivity Substrate (Thermo Fisher Scientific Inc., and quantified using ImageJ software (v1.63, National Institutes of Health).

Rat model of vascular injury and treatment regimens. To assess the therapeutic effects of different regimens (AMD3100 alone, SDF-1 alone or AMD3100 combined with SDF-1) in promoting reendothelialization after vascular injury, 220 female Sprague-Dawley (SD) rat (age: 10 weeks; weight: 250-300 g; Nanjing Better Biotechnology Co Ltd.) were used to create a model of carotid artery injury as described previously (6). Briefly, vascular endothelium was injured by guidewire, as used in percutaneous transluminal angioplasty. The operation was performed under anesthesia with pentobarbital sodium $(30 \mathrm{mg} / \mathrm{kg})$. Then the bifurcation of the left carotid artery was exposed, and the common, internal and external carotid arteries were separated to temporarily restrict blood flow. The common carotid artery was denuded three times with a $0.38-\mathrm{mm}$ flexible angioplasty guidewire through the external carotid artery. The total length of denudation was $5 \mathrm{~mm}$ from the bifurcation of carotid arteries. The external carotid artery was permanently ligated after removing the wire, and the temporary ligatures were released to allow blood flow to be restored followed by skin suture. Following injury of the common carotid artery, the SD rats were randomly divided into four groups ( $\mathrm{n}=55$ per group): Control group (treated with saline), group A (AMD3100 alone), group S (SDF-1 alone) and group AS (AMD3100 combined with SDF-1). The treatment was performed as follows: i) In group AS, AMD3100 (5 mg/kg) was injected via the tail vein immediately after the artery injury model was established, followed by injection of SDF-1 $(1 \mu \mathrm{g} / \mathrm{kg})$ at 1,6 and $12 \mathrm{~h}$; ii) in group A, AMD3100 was injected into the tail vein immediately after the artery injury model was established; iii) in group $\mathrm{S}$, an equivalent volume of saline was used instead of AMD3100, and then SDF-1 was administered locally at 1, 6 and $12 \mathrm{~h}$ after administration of saline; iv) only an equivalent volume of saline was used in the control group. All rats were housed in a constant temperature room $\left(25-27^{\circ} \mathrm{C}\right.$; humidity, 40-50\%) with food and water ad libitum, under a 12-h light/dark cycle.

Flow cytometric analysis of the number of EPCs in the peripheral blood of each group. Flow cytometry was performed to detect the number of EPCs in the peripheral blood of rats in each group after treatment. Briefly, mononuclear cells (MNCs) were isolated from the peripheral blood at baseline, and $1,6,12,24$ and $48 \mathrm{~h}$ after treatment. The blood sample was collected from the jugular vein, and then diluted in PBS at a ratio of 1:1. The MNCs were isolated from cell suspension via gradient centrifugation $(1,500 \mathrm{x}$ g) for $10 \mathrm{~min}$ at room temperature, and the number of EPCs in the peripheral blood was determined by flow cytometry. EPCs were defined as CD34 ${ }^{+}$ kinase insert domain receptor $(\mathrm{KDR})^{+}$cells. Briefly, MNCs were first incubated with $0.5 \% \mathrm{BSA}$, and then incubated with allophycocyanin (APC)-conjugated anti-mouse CD34 (Abcam; ab155377) and phycoerythrin-conjugated anti-mouse KDR antibodies (Abcam; ab253080) or isotype antibody (10 $\mu \mathrm{l} / \mathrm{tube})$ for $10 \mathrm{~min}$ in the dark at $4^{\circ} \mathrm{C}$. MNCs were washed once with PBS, followed by flow cytometry using a NAVIOS flow cytometer (Beckman Coulter, Inc.) according to the manufacturer's protocol. The results were analyzed using FlowJo 7.6 software (FlowJo LLC).

Immunofluorescence analysis of the number of EPCs recruited to the injury site. A denuded artery of each group was separated and harvested from the rat one day after treatment to evaluate the number of EPCs recruited to the injury site. Samples were fixed in $10 \%$ formalin for $24 \mathrm{~h}$ at room temperature and embedded in paraffin using standard methods. For immunohistochemistry, paraffin-embedded sections $(4 \mu \mathrm{m})$ were heated at $60^{\circ} \mathrm{C}$ for $30 \mathrm{~min}$, cleared with xylol and anhydrous alcohol and rehydrated in descending alcohol series. For antigen retrieval the sections were blocked with $10 \%$ goat serum (Gibco; Thermo Fisher Scientific, Inc.) diluted 1:10 for $30 \mathrm{~min}$ at room temperature. Subsequently, the injured artery was incubated with rabbit anti-mouse CD34 (1:100; Abcam; ab81289) and murine anti-mouse KDR (1:100; Abcam; ab9530) primary antibodies for overnight at $4^{\circ} \mathrm{C}$, and FITC-(1:50; Wuhan Boster Biological Technology, Ltd.; BM2012) or APC-conjugated secondary antibodies (1:50; Wuhan Boster Biological Technology, Ltd.; BA1011) for $1 \mathrm{~h}$ at room temperature. Three fields were randomly selected for imaging under an Olympus BX53 biological fluorescence microscope (magnification, $\mathrm{x} 400$; Olympus Corporation).

Histological assessment. Reendothelialization and neointimal hyperplasia were assessed at 7 and 14 days after treatment 
as described in our previous study (6). All operations were performed under anesthesia with pentobarbital sodium via intraperitoneal injection $(30 \mathrm{mg} / \mathrm{kg})$. A pathologist who was blinded to the treatment regimen assessed all specimens. Analysis of the digitalized images was performed using ImageJ 1.63 software (National Institutes of Health).

Neointimal hyperplasia was evaluated using hematoxylin and eosin (H\&E) staining. Briefly, following anesthesia with $30 \mathrm{mg} / \mathrm{kg}$ pentobarbital sodium, cardiac perfusion was conducted by perfusing PBS via the bilateral jugular vein until the effluent ran clear, followed by fixation with formaldehyde for $5 \mathrm{~min}$. Subsequently, the carotid arteries were excised from the rats, and the specimens were fixed in $10 \%$ formalin for $24 \mathrm{~h}$ at room temperature. Subsequently, separated vessels $(5 \mathrm{~mm})$ were embedded in paraffin and sectioned at $4 \mu \mathrm{m}$ ). Sections were stained with $\mathrm{H} \& \mathrm{E}$ staining kit (Beijing Solarbio Science $\&$ Technology Co., Ltd., G1120) for $2 \mathrm{~h}$ at room temperature according to the manufacturer's protocol. Neointimal thickness was assessed in terms of the intima/media area ratio, and was measured in H\&E-stained axial sections. A pathologist who was blinded to the treatment regimen investigated all specimens. Analysis of the digitalized images was performed using ImageJ 1.63 software (National Institutes of Health).

Reendothelialization was assessed using Evans blue staining. Briefly, $0.5 \mathrm{ml} 0.5 \%$ Evans blue dye was injected intravenously via the tail vein $30 \mathrm{~min}$ before the rats were scarified. Subsequently, cardiac perfusion was used to perfuse PBS via the bilateral jugular vein until the effluent ran clear, followed by fixation with $4 \%$ formaldehyde for $5 \mathrm{~min}$ at room temperature. The common carotid artery was harvested at $4 \mathrm{~mm}$ from the bifurcation and opened longitudinally. The areas stained and unstained in blue were measured in the entire injured area, and the rate of reendothelialization (unstained area/total area) was used to determine the difference in reendothelialization among all groups. The analysis of digitalized images was performed using ImageJ 1.63 software (National Institutes of Health).

Statistical analysis. Data are presented as the mean \pm standard deviation. One-way ANOVA with Tukey's post hoc test was used to determine statistically significant differences among the same treatment group at different time points in the proliferation assay, or among subgroups. SPSS 20.0 software (IBM Corp.) was used to perform statistical analysis. $\mathrm{P}<0.05$ was considered to indicate a statistically significant difference.

\section{Results}

Characteristics of EPCs.EPCs appeared round or spindle-shaped at day 4, and then typical cell clusters appeared after 7-10 days of culture. After 21 days of culture, the cells formed colonies and appeared pebble-shaped. Flow cytometry revealed that the EPCs in the present study were positive for CD34 and KDR, while they were negative for CD45. Furthermore, these cells could take up acetylated LDL and bind to Ulex europaeus agglutinin I. These characteristics identified the cells as EPCs (Fig. 1A-C).

Proliferation of EPCs is attenuated by AMD3100, whereas it is enhanced by SDF-1. Proliferation curves were plotted to reveal the proliferative activity of EPCs after treatment with AMD3100 or SDF-1 at various concentrations and different time points. Furthermore, the $\mathrm{EC}_{50}$ of AMD3100 and SDF-1 was calculated for subsequent experiments based on the proliferation curves. The results revealed that AMD3100 reduced the proliferation of EPCs effectively at various concentrations compared with the control group (Fig. 2A). The $\mathrm{EC}_{50}$ of AMD3100 was $34 \mathrm{nM}$ (Fig. 2B). By contrast, SDF-1 could promote proliferation of EPCs at various concentrations in a concentration-dependent manner (Fig. 2C). The $\mathrm{EC}_{50}$ of SDF-1 was $212 \mathrm{nM}$ (Fig. 2D).

AMD3100 stimulates adhesion of EPCs to HUVECs rather than FN, while SDF-1 stimulates adhesion of EPCs to HUVECs and FN. Adhesion assays demonstrated that fewer EPCs adhered to FN after treatment with AMD3100 [60.3 \pm 20.1 (group A) vs. 80.7 \pm 16.7 (control group) cells/field, $\mathrm{P}=0.042 ; 60.3 \pm 20.1$ (group A) vs. 105.4 \pm 17.1 (group $\mathrm{S})$ cells/field, $\mathrm{P}=0.007]$, whereas following treatment with AMD3100, more EPCs adhered to HUVECs compared with the control group [45.2 \pm 16.8 (group A) vs. $22.3 \pm 4.5$ (control group) cells/field, $\mathrm{P}=0.029]$. Additionally, treatment with SDF-1 significantly enhanced the adhesion capacity of EPCs to both FN $[105.4 \pm 17.1$ (group S) vs. 80.7 \pm 16.7 (control group) cells/field, $\mathrm{P}=0.02]$ and HUVECs $[52.7 \pm 12.6$ (group S) vs. $22.3 \pm 4.5$ (control group) cells/field, $\mathrm{P}=0.031]$. Furthermore, the adhesion capacities of EPCs to HUVECs in groups $\mathrm{S}$ and A were not identified to be significantly different $[52.7 \pm 12.6$ (group S) vs. $45.2 \pm 16.8$ (group A) cells/field, $\mathrm{P}=0.23$ ]. The present study further revealed that AMD3100 impaired the SDF-1-mediated adhesion capacity of EPCs to FN [65.6 \pm 11.5 (group AS) vs. 105.4 \pm 17.1 (group S) cells/field, $\mathrm{P}=0.015$; $65.6 \pm 11.5$ (group AS) vs. 80.7 \pm 16.7 (control group) cells/field, $\mathrm{P}=0.047]$. By contrast, even more EPCs adhered to HUVECs in group AS compared with in the control group [62.7 \pm 17.4 (group AS) vs. $22.3 \pm 4.5$ (control group) cells/field, $\mathrm{P}=0.029]$. The effect of AMD3100 combined with SDF-1 on the adhesion capacity of EPCs to HUVECs was greater than that of AMD3100 [62.7 \pm 17.4 (group AS) vs. $45.2 \pm 16.8$ (group A) cells/field, $\mathrm{P}=0.031$ ]. The detailed results are shown in Fig. 3A.

AMD3100 only stimulates the expression levels of CXCR7, while SDF-1 upregulates the expression levels of CXCR4 and CXCR7 in EPCs. Both CXCR4 and CXCR7 are involved in regulating the function of EPCs; therefore, the present study evaluated the expression levels of CXCR4 and CXCR7 in EPCs before and after treatment. Confocal immunofluorescence microscopy revealed that both CXCR4 and CXCR7 were expressed by EPCs (Fig. 3B), and AMD3100 treatment upregulated the expression levels of CXCR7 in EPCs. In addition, the expression levels of CXCR4 and CXCR7 were significantly increased after incubation with SDF-1 or AMD3100 combined with SDF-1 for $24 \mathrm{~h}$ compared with the control group. Furthermore, upregulation of CXCR7 was identified in group AS compared with in groups A and $\mathrm{S}$. The expression levels of CXCR4 in group $\mathrm{S}$ were higher than those in group A. However, the expression levels of CXCR7 were similar in groups S and A (Fig. 3C).

AMD3100 mobilizes circulating EPCs and promotes the incorporation of EPCs into the injury site, while SDF-1 does not. Different treatment regimens were used to reveal the effects of AMD3100, SDF-1 or AMD3100 combined with SDF-1 in vivo. 
A
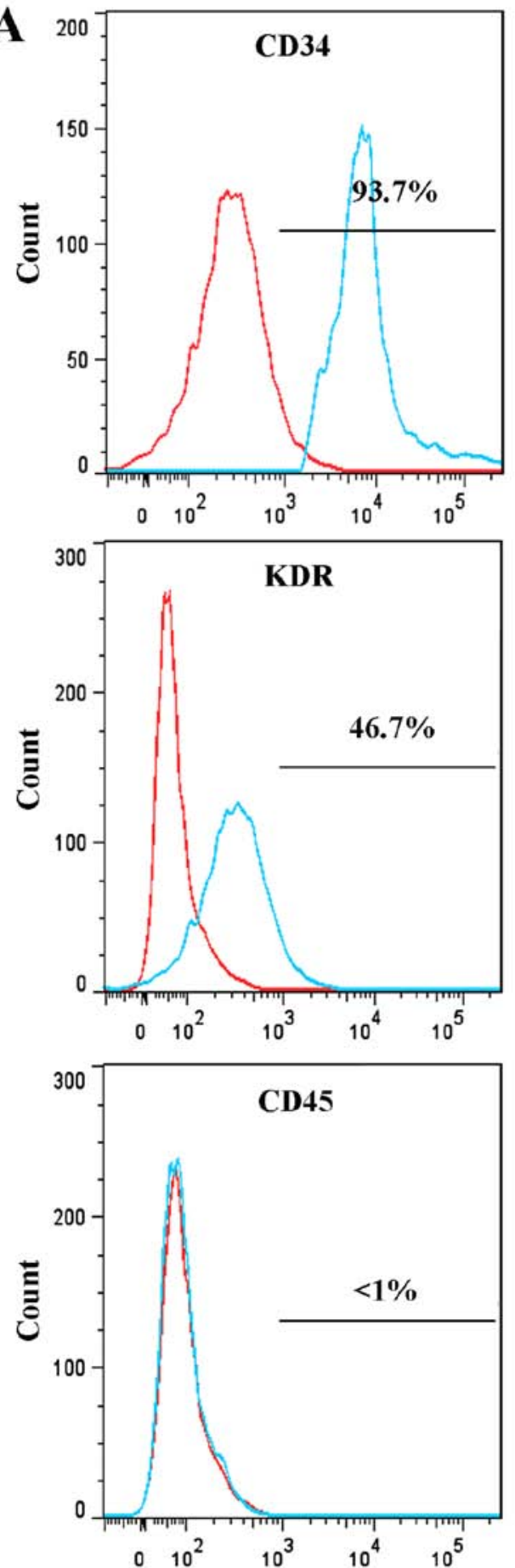

B
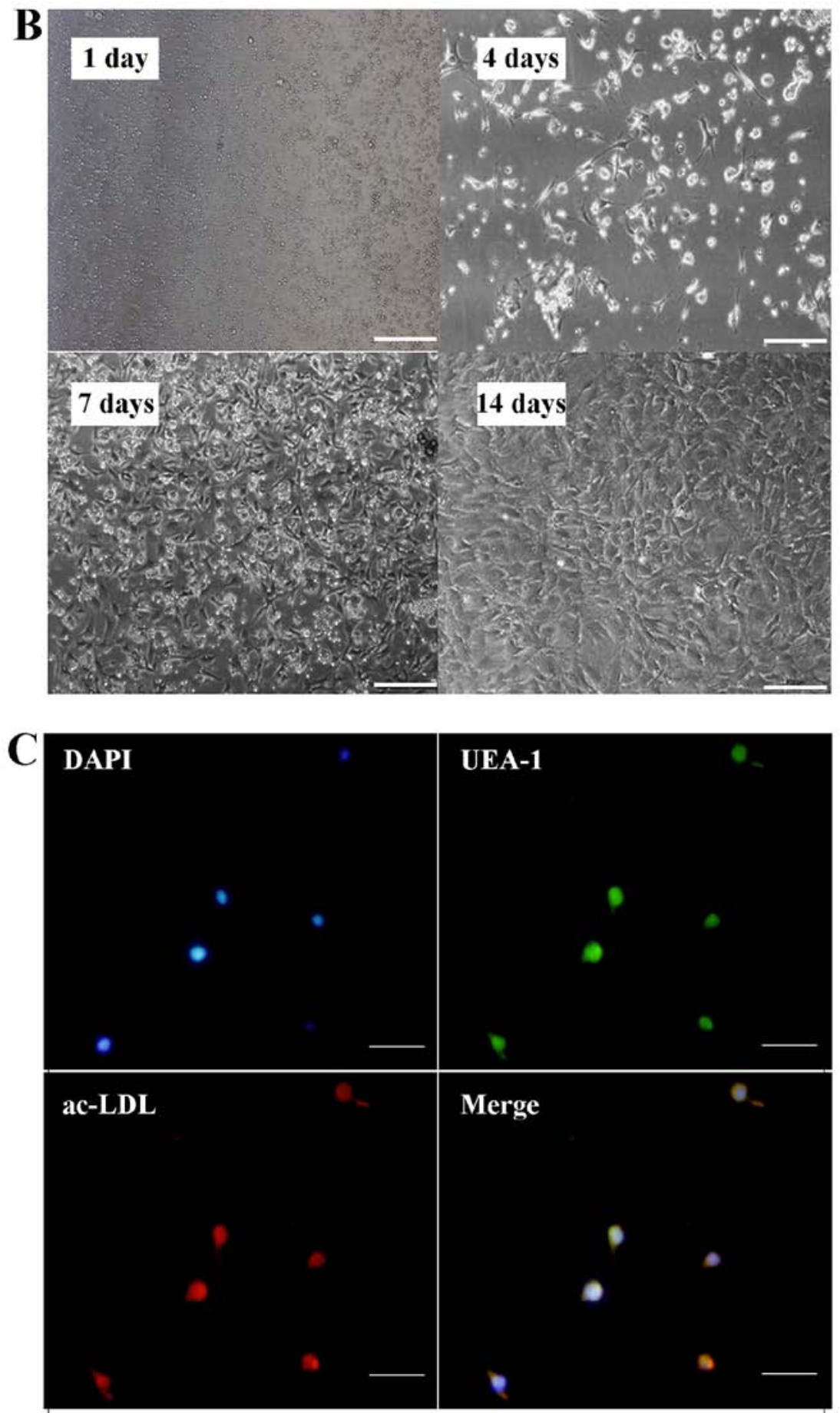

Figure 1. Characteristics of EPCs. (A) Fluorescence-activated cell sorting revealed that EPCs used in the present study were positive for CD34 and KDR, whereas they were negative for CD45. (B) Typical features of EPCs at day 1, 4, 7 and 14. (C) EPCs could take up ac-LDL and bind to UEA-1. Scale bar, $150 \mu$ m. ac-LDL, acetylated low-density lipoprotein; EPCs, endothelial progenitor cells; KDR, kinase insert domain receptor; UEA-1, Ulex europaeus agglutinin I.

The circulating EPCs were increased in group A compared with in the control group at 1, 6, 12 and $24 \mathrm{~h}$ after treatment. The number of circulating EPCs was significantly increased after $1 \mathrm{~h}$ and reached the peak at $6 \mathrm{~h}$ after treatment with AMD3100. However, treatment with SDF-1 did not mobilize circulating EPCs (Fig. 4A). An immunofluorescence assay revealed that an increased number of EPCs were recruited to the site of endothelial injury in group A compared with in the control group $[16.7 \pm 1.2$ (group A) vs. $7.3 \pm 0.9$ (control group) cells/field; $\mathrm{P}=0.041]$. However, treatment with $\mathrm{SDF}-1$ did not recruit more EPCs to the site of endothelial injury $[8.7 \pm 1.1$ (group S) vs. $7.3 \pm 0.9$ (control group) cells/field, $\mathrm{P}=0.52$ ] (Fig. 4B). Notably, pretreatment with AMD3100, followed by local administration of SDF-1, recruited significantly more EPCs to the site of vascular injury compared with AMD3100 treatment alone $[22.8 \pm 1.3$ (group AS) vs. 16.7 \pm 1.2 (group A) cells/field, $\mathrm{P}=0.049$ ].

AMD3100 combined with SDF-1 promotes reendothelialization and inhibits neointimal hyperplasia more effectively than 

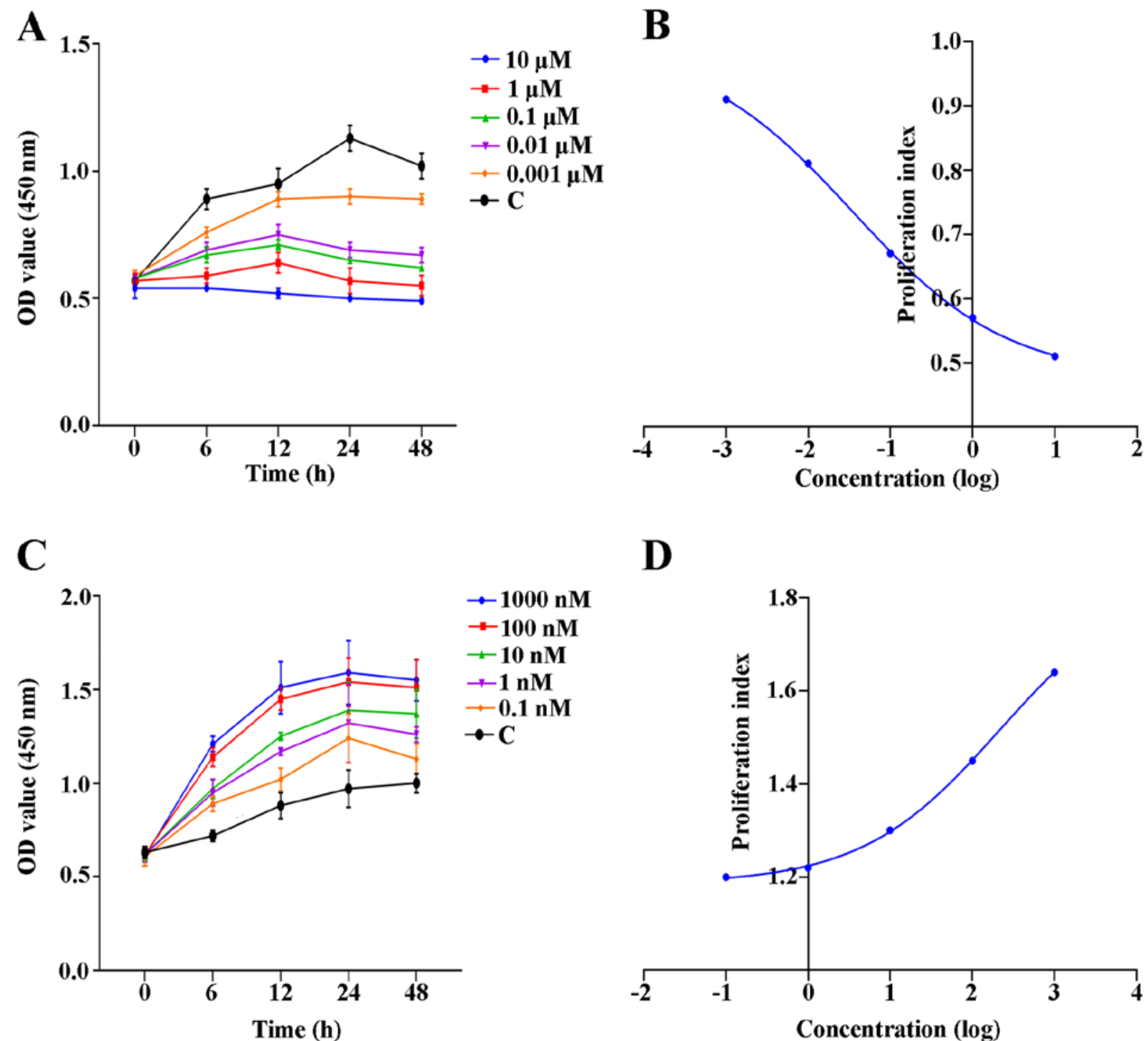

Figure 2. Proliferation curve and $\mathrm{EC}_{50}$ values are influenced by AMD3100 and SDF-1. (A) Proliferation curve of EPCs following treatment with AMD3100 at various concentrations. (B) $\mathrm{EC}_{50}$ of AMD3100 was calculated based on the proliferation curve. (C) Proliferation curve of EPCs after treatment with SDF-1 at various concentrations. (D) $\mathrm{EC}_{50}$ of SDF-1 was calculated based on the proliferation curve. $\mathrm{EC}_{50}, 50 \%$ effective concentration; EPCs, endothelial progenitor cells; OD, optical density; SDF-1, stromal cell-derived factor 1.

ADM3100 alone. Increased reendothelialization was identified in groups A and AS at 7 days after treatment compared with in the control group [ $80.4 \pm 6.1$ (group A) vs. $46.3 \pm 4.2 \%$ (control group), $\mathrm{P}<0.001 ; 92.7 \pm 7.6$ (group AS) vs. $46.3 \pm 4.2 \%$ (control group), $\mathrm{P}<0.001]$, and there was a significant difference in reendothelialization between groups AS and A at day 7. By contrast, no significant difference was observed in reendothelialization after 14 days $[97.2 \pm 5.9$ (group A) vs. $92.3 \pm 4.7 \%$ (control group), $\mathrm{P}=0.412 ; 98.5 \pm 7.2$ (group AS) vs. $92.3 \pm 4.7 \%$ (control group), $\mathrm{P}=0.43]$. However, early reendothelialization inhibited neointimal hyperplasia after 7 and 14 days of treatment in group A [7 days, $0.35 \pm 0.09$ (group A) vs. $0.47 \pm 0.05$ (control group), $\mathrm{P}=0.023 ; 14$ days, $0.47 \pm 0.08$ (group A) vs. $0.64 \pm 0.07$ (control group), $\mathrm{P}=0.071]$ and group AS [7 days, $0.24 \pm 0.06$ (group AS) vs. $0.47 \pm 0.05$ (control group), $\mathrm{P}<0.001$; 14 days, $0.27 \pm 0.05$ (group AS) vs. $0.64 \pm 0.07$ (control group), $\mathrm{P}<0.001]$. The difference in the levels of reendothelialization of group $\mathrm{S}$ compared with the control group was not statistically significant at day $7[51.2 \pm 5.4$ (group S) vs. $46.3 \pm 4.2 \%$ (control group), $\mathrm{P}=0.22]$ and day 14 [91.1 \pm 7.6 (group $\mathrm{S}$ ) vs. $92.3 \pm 4.7 \%$ (control group), $\mathrm{P}=0.517]$, and neointimal hyperplasia was not attenuated in this group [7 days, $0.45 \pm 0.07$ (group $S$ ) vs. $0.47 \pm 0.05$ (control group), $\mathrm{P}=0.049 ; 14$ days, $0.63 \pm 0.04$ (group S) vs. $0.64 \pm 0.07$ (control group), $\mathrm{P}=0.43$ ] (Fig. 5).

\section{Discussion}

AMD3100 and SDF-1 are extensively used in regenerative medicine, including hematological disease $(14,19)$, angiogenesis $(17,20)$, intimal repairing $(16)$, wound healing $(21,22)$ and brain repair after ischemic stroke $(18,23)$. Furthermore, previous studies have reported that AMD3100 and SDF-1 may be involved in mobilization and recruitment of EPCs $(16,17,24,25)$. These studies indicated that AMD3100 or SDF-1 may be used for endothelial regeneration. The present study assessed the effects of AMD3100 and SDF-1 on endothelial regeneration. Additionally, the effects of AMD3100 and SDF-1 on EPCs were evaluated. 

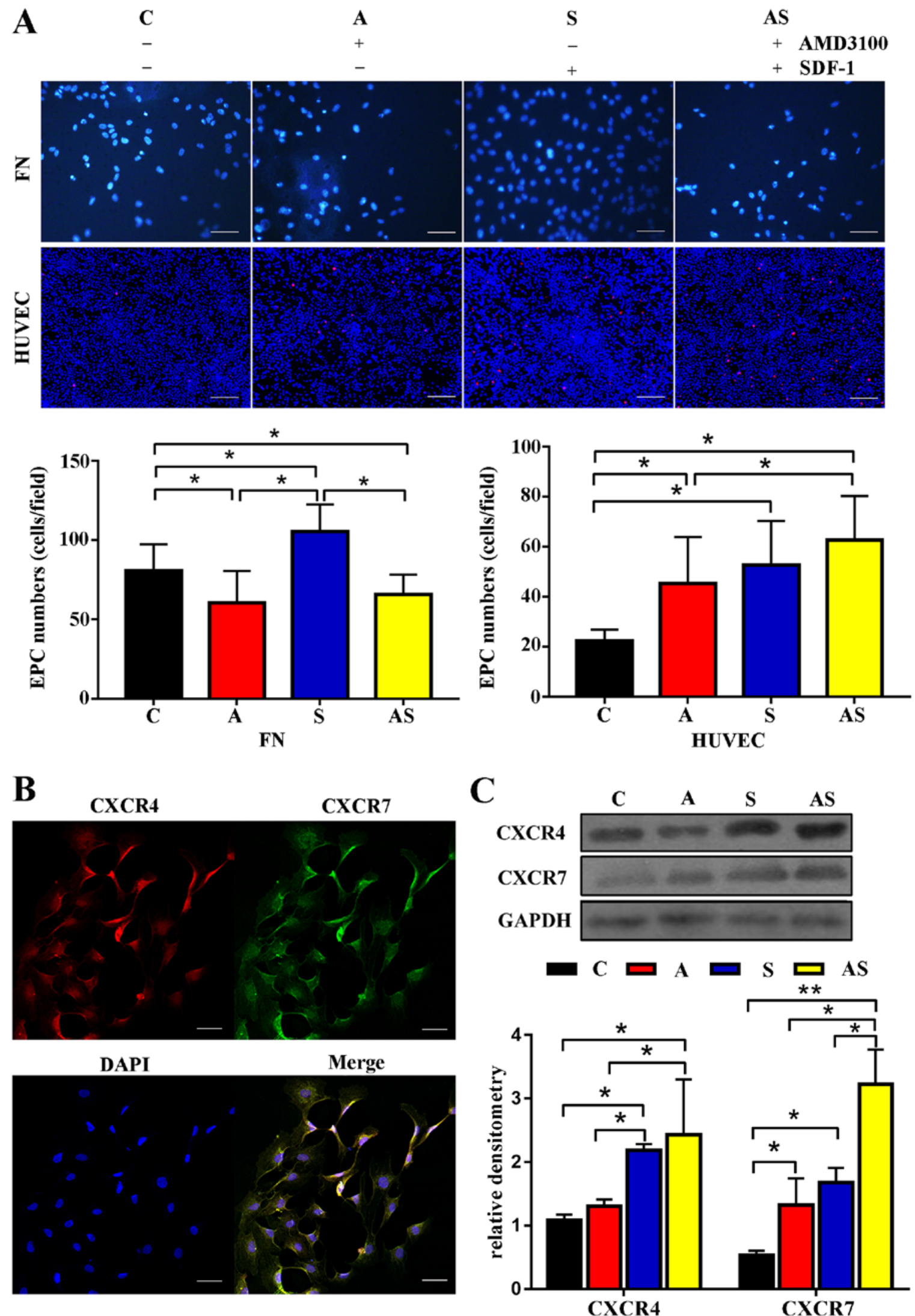

Figure 3. Adhesion capacity, and the expression levels of CXCR4 and CXCR7 are affected by AMD3100 and SDF-1 treatment. (A) Adhesion capacity to FN was impaired by AMD3100 treatment, whereas AMD3100 treatment stimulated the adhesion capacity to HUVECs. A similar tendency was observed after treatment with AMD3100 combined with SDF-1. Scale bar, $25 \mu \mathrm{m}$. (B) Confocal immunofluorescence microscopy confirmed that both CXCR4 and CXCR7 were expressed in EPCs. Scale bar, $100 \mu \mathrm{m}$. (C) Western blotting revealed that treatment with AMD3100 upregulated the expression levels of CXCR7 but not CXCR4. However, SDF-1 or AMD3100 combined with SDF-1 upregulated the expression levels of CXCR4 and CXCR7. Furthermore, the effects of AMD3100 combined with SDF-1 on the expression levels of CXCR7 were the greatest among the four groups. $\mathrm{n}=5 .{ }^{*} \mathrm{P}<0.05 ;{ }^{* *} \mathrm{P}<0.001$. C, control; A, AMD3100 alone; S, SDF-1 alone; AS, AMD3100 combined with SDF-1; CXCR, C-X-C motif chemokine receptor; EPCs, endothelial progenitor cells; FN, fibronectin; HUVECs, human umbilical vein endothelial cells; SDF-1, stromal cell-derived factor 1. 

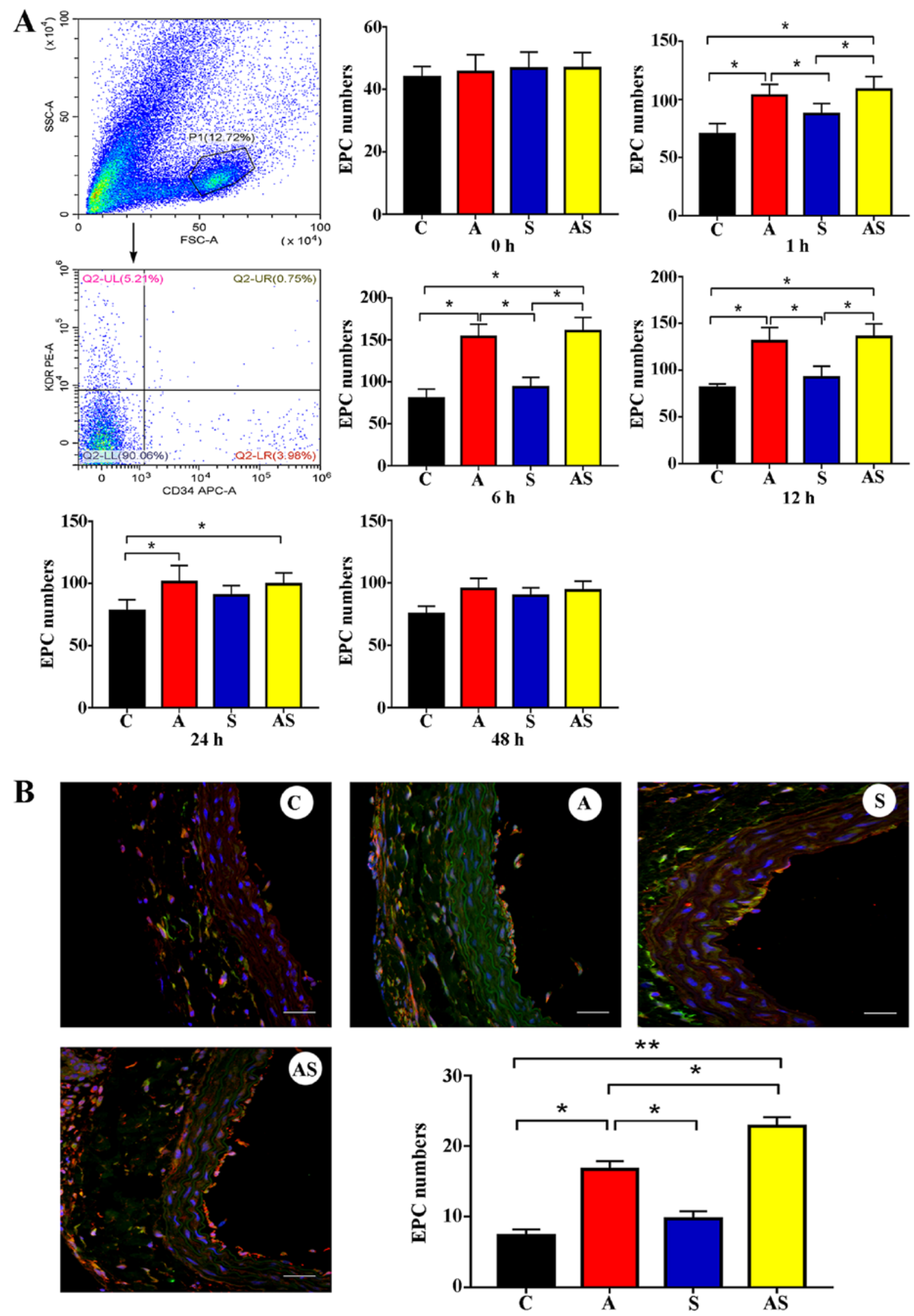

Figure 4. Number of EPCs in circulation and at the injury site. (A) AMD3100 treatment could effectively mobilize circulating EPCs in a time-dependent manner. However, SDF-1 treatment did not increase the number of circulating EPCs at any time point. Additionally, AMD3100 combined with SDF-1 (group AS) increased the number of circulating EPCs. However, there was no significant difference in circulating EPCs observed between group A and group AS. (B) AMD3100 treatment recruited more EPCs to the injury site. SDF-1 treatment did not increase the number of EPCs at the injury site. However, pretreatment with AMD3100, followed by local administration of SDF-1 recruited more EPCs to the injury site. The effects of AMD3100 combined with SDF-1 (group AS) on recruitment of EPCs were stronger than those of AMD3100 alone. Scale bar, $50 \mu \mathrm{m} . \mathrm{n}=5$. " $\mathrm{P}<0.05$; ${ }^{* *} \mathrm{P}<0.001$. C, control; A, AMD3100 alone; S, SDF-1 alone; AS, AMD3100 combined with SDF-1; EPCs, endothelial progenitor cells; SDF-1, stromal cell-derived factor 1. 
A

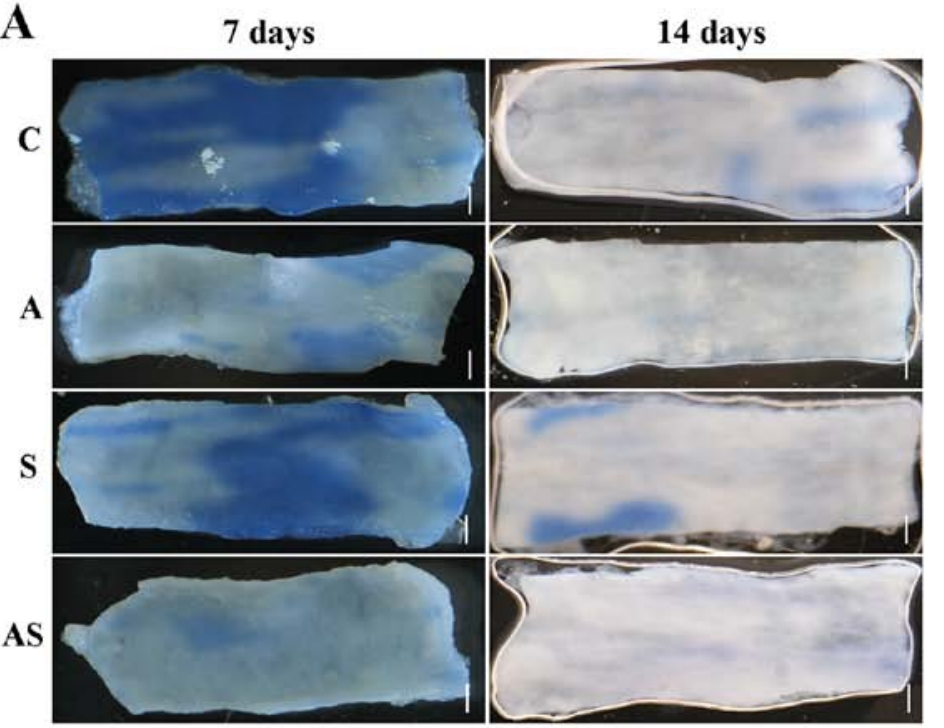

B
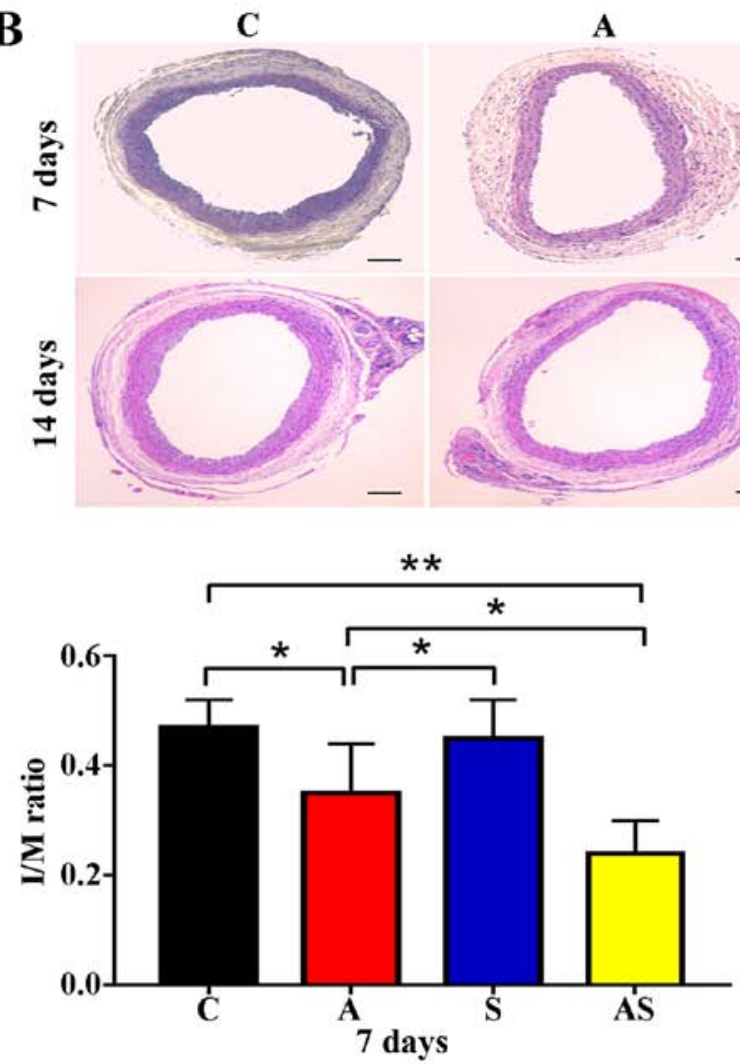

A
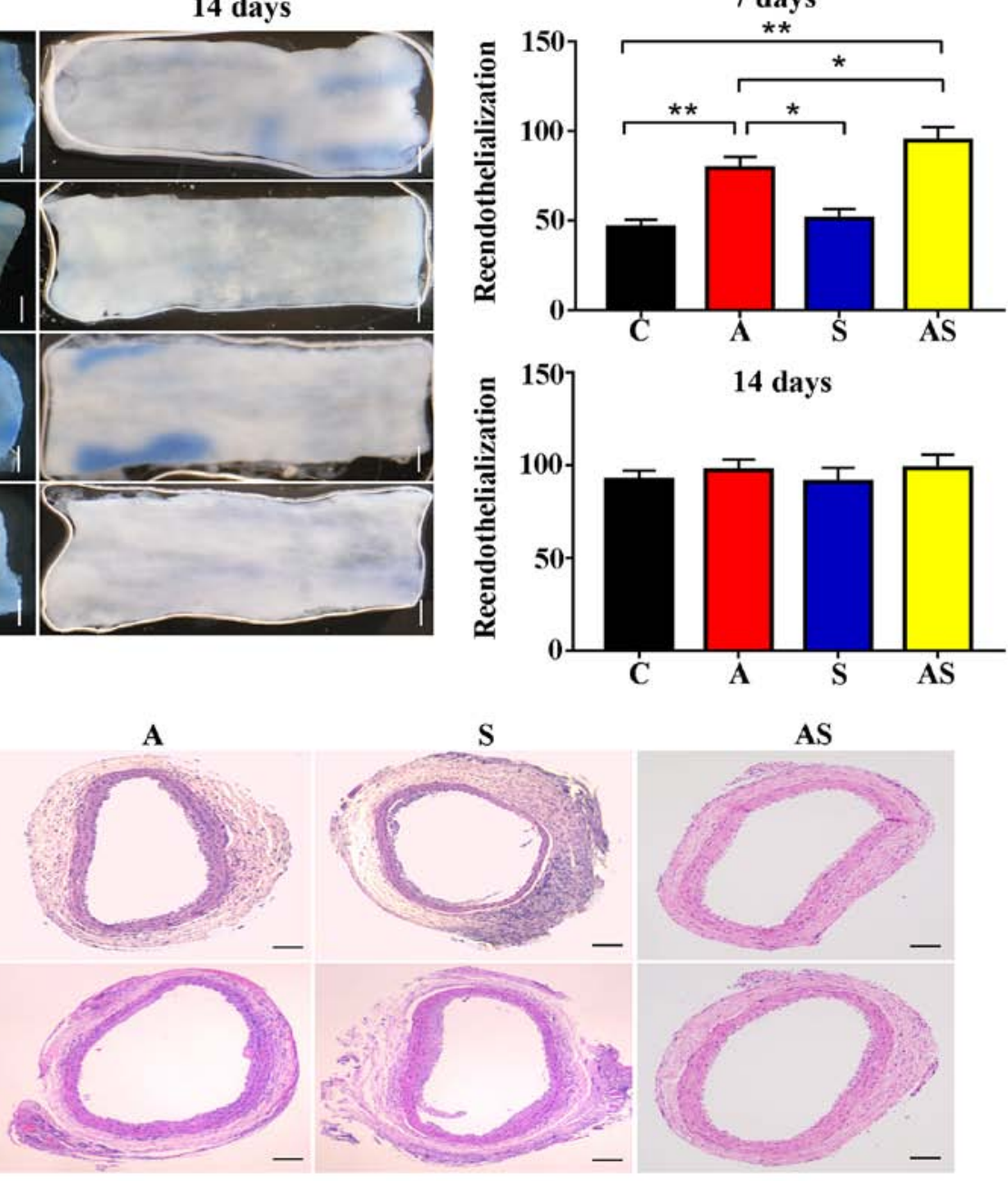

$\mathbf{S}$

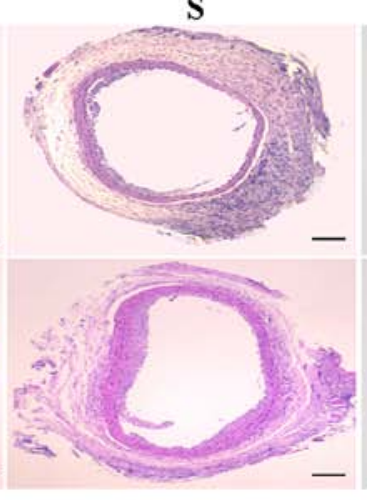

AS

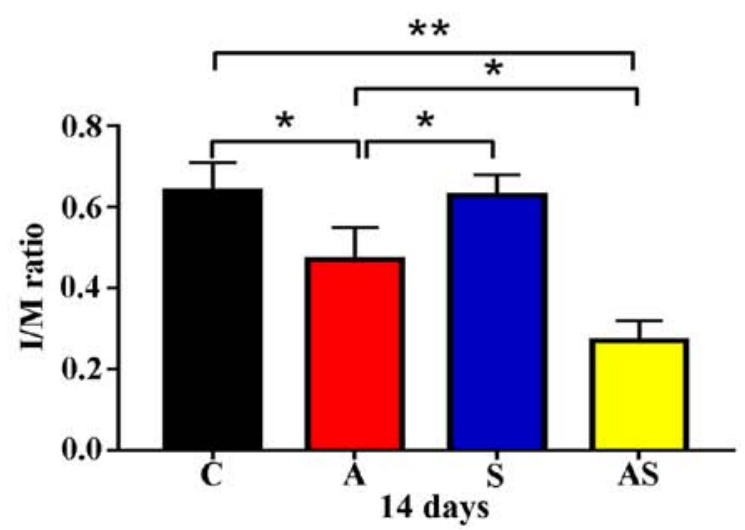

Figure 5. Effects of AMD3100 and SDF-1 treatment on intimal repair. (A) AMD3100 and AMD3100 combined with SDF-1 promoted reendothelialization compared with the control treatment 7 days after treatment. Furthermore, the treatment effects of the combination of AMD3100 and SDF-1 on reendothelialization were greater than those of AMD3100 treatment alone. Scale bar, $500 \mu \mathrm{m}$. (B) Early reendothelialization reduced neointimal hyperplasia in groups A and AS. The treatment effects of the combination of AMD3100 and SDF-1 were the most prominent among the four groups. Scale bar, $100 \mu \mathrm{m}$. $\mathrm{n}=5$. ${ }^{*} \mathrm{P}<0.05$; ${ }^{* *} \mathrm{P}<0.001$. C, control; A, AMD3100 alone; S, SDF-1 alone; AS, AMD3100 combined with SDF-1; I/M ratio, intima/media ratio; SDF-1, stromal cell-derived factor 1 .

Intravenous or subcutaneous administration of AMD3100 has been reported to effectively induce mobilization of HSCs and EPCs (14,24). Furthermore, a single dose of AMD3100 may mobilize EPCs into peripheral blood (25). Similar to previous studies $(13,25)$, the present study noted that a single dose of AMD3100 was sufficient to mobilize EPCs into circulation. Furthermore, the results of the present study indicated that increased numbers of EPCs were involved in reendothelialization following AMD3100 treatment. The underlying mechanism by which AMD3100 treatment recruits more EPCs to participate in endothelial repair is unclear. The in vivo and in vitro results reported in the present study revealed that endothelial cells (ECs) at the injury site may be crucial for intimal repair after AMD3100 treatment, as it was observed that more EPCs 
adhered to HUVECs compared with FN after AMD3100 treatment. Moreover, more EPCs were recruited into endothelial site after intravenous injection of AMD3100. However, the detailed mechanism should be considered in a further study. In addition, the mismatch between the time circulating EPCs reached their highest level after AMD3100 treatment and the median terminal half-life of AMD3100 may contribute to EPCs ability to mediate intimal repair. Stewart et al (26) reported that the median terminal half-life of AMD3100 in circulation was $4.6 \mathrm{~h}$. However, in the present study, the number of circulating EPCs reached its peak at $6 \mathrm{~h}$ and remained at high levels for $24 \mathrm{~h}$ after AMD3100 treatment. The aforementioned inhibitory effect of AMD3100 on EPCs was attenuated before circulating EPCs decreased to baseline levels, as a result, more circulating EPCs were recruited to the arterial injury site.

A previous study demonstrated that a decrease in the level of SDF-1 at the injury site was associated with delayed reendothelialization as fewer EPCs were recruited to the injury site (27). By contrast, local accumulation of fluorescence-labeled EPCs was observed in ischemic muscle after local injection of SDF-1 in an athymic rat hind limb ischemia model (28). Therefore, it may be concluded that local accumulation of SDF-1 is essential for recruitment of endothelial progenitors and in accelerating repair of injury. Thus, the present study also assessed the effects of SDF-1 on intimal repair via local injection. However, the results of the present study indicated that local injection of SDF-1 was ineffective in promoting reendothelialization. Hence, it was revealed that insufficient EPCs in circulation were the main contributing factor for delayed recovery of injury after SDF-1 treatment. Additionally, it was revealed that AMD3100 combined with SDF-1 had superior therapeutic effects compared with AMD3100 alone.

Previous studies have demonstrated that SDF-1 may be involved in regulating the mobilization, proliferation and adhesion capacity of EPCs through binding to CXCR4 and CXCR7 (15,29,30). In accordance with these studies, the present study revealed that SDF-1 treatment stimulated the proliferation and adhesion capacity of EPCs to FN and HUVECs. Furthermore, the present study demonstrated that in EPCs the expression levels of CXCR4 and CXCR7 were upregulated after SDF-1 treatment. The results indicated that SDF-1 exerted its positive regulatory effects on cellular function not only via binding to and activating its receptor, but also by upregulating the expression levels of CXCR4 and CXCR7. However, the molecular mechanism by which SDF-1 can stimulate EPCs to upregulate the expression levels of CXCR4 and CXCR7 needs to be investigated further. The effects of AMD3100 on cellular function of EPCs were also evaluated in the present study. A previous study demonstrated that AMD3100 impaired the proliferation, migration and adhesion capacity of EPCs via blocking the SDF-1/CXCR4 axis (31). The present results demonstrated that AMD3100 could positively modulate adhesion of EPCs to HUVECs via upregulation of the expression levels of CXCR7. It remains elusive how AMD3100 can stimulate upregulation of the expression levels of CXCR7 in EPCs. However, previous studies have demonstrated that CXCR7 may be crucial in regulating cell adhesion capacity, particularly the adhesion capacity to HUVECs $(29,30,32)$. Furthermore, Kalatskaya et al (33) revealed that AMD3100 may bind to CXCR7 and positively modulate the effect of CXCL12 by inducing $\beta$-arrestin recruitment to CXCR7. The aforementioned data indicated that AMD3100 stimulated adhesion of EPCs to HUVECs via upregulation of the expression levels of CXCR7 rather than CXCR4.

The present study demonstrated that the adhesive activity of EPCs was pivotal for EPCs recruitment and EPC-mediated endothelial repair. Furthermore, the in vitro results showed that CXCR4 and CXCR7 molecules were associated with the adhesive activity of EPCs after AMD3100 or SDF-1 treatment. Previous studies identified that other molecules, including P-selectin (34) and E-selectin (35), and very late antigen-4 and its ligand vascular cell adhesion molecule 1 (36) also contribute to the cellular adhesion capacity of progenitor cells. All these results indicated that upregulating these adhesive molecules may contribute to the adhesive activity of EPCs and EPC-mediated intimal repair. However, the present study was still inadequate and these underlying mechanisms should be considered in the future.

There were several limitations of the present study. Firstly, knockdown of CXCR4 and CXCR7 was not performed to identify the detailed molecular mechanism by which SDF-1/CXCR4 and SDF-1/CXCR7 are involved in regulating cellular function of EPCs after treatment with AMD3100 or SDF-1. This should be investigated in future studies. Secondly, the molecular mechanisms by which EPCs exhibited upregulated expression levels of CXCR4 and CXCR7 after treatment with AMD3100 or SDF-1 remain unclear. In addition, only $46.7 \%$ cells positive for KDR. The main reason underlying this phenomenon may due to EPCs showing more characteristics of progenitor cells but fewer characteristics of mature endothelial cells.

In conclusion, AMD3100 positively regulated the cell adhesion capacity of EPCs to HUVECs via elevation of the expression levels of CXCR7 rather than CXCR4, whereas SDF-1 stimulated cell proliferation and the adhesion capacity of EPCs to FN and HUVECs by increasing the expression levels of CXCR4 and CXCR7. Treatment with AMD3100 accelerated reendothelialization and inhibited neointimal hyperplasia after endothelial injury, whereas SDF-1 treatment alone failed to promote endothelial regeneration. AMD3100 combined with SDF-1 outperformed AMD3100 alone, promoted early reendothelialization and inhibited neointimal hyperplasia, indicating that early reendothelialization attenuates neointimal hypoplasia following endothelial injury.

\section{Acknowledgements}

Not applicable.

\section{Funding}

The present study was financially supported by the National Natural Science Foundation of China (grant nos. 81271683 and 81671791) and the Shanghai Key Discipline of Medical Imaging (grant no. 2017ZZ02005).

\section{Availability of data and materials}

The datasets used and/or analyzed during the current study are available from the corresponding author on reasonable request. 


\section{Authors' contributions}

CJ, XM and RL performed the experiments. JZ designed the experiments. $\mathrm{HH}$ conducted the statistical analysis of the data. CJ, RL and XM drafted the manuscript. JG and JZ conceived the study, participated in its design and coordination, and helped to draft the manuscript. All authors read and approved the final manuscript.

\section{Ethics approval and consent to participate}

All procedures involving human beings and animals were reviewed and approved by the Ethics Committee of Shanghai Sixth People's Hospital (Shanghai, China). All clinical investigations were conducted according to the principles of the Declaration of Helsinki. All patients provided written informed consent prior to the start of the study.

\section{Patient consent for publication}

Not applicable.

\section{Competing interests}

The authors declare that they have no competing interests.

\section{References}

1. Cassese S, Byrne RA, Tada T, Pinieck S, Joner M, Ibrahim T, King LA, Fusaro M, Laugwitz KL and Kastrati A: Incidence and predictors of restenosis after coronary stenting in 10004 patients with surveillance angiography. Heart 100: 153-159, 2014.

2. Alfonso F, Byrne RA, Rivero F and Kastrati A: Current treatment of in-stent restenosis. J Am Coll Cardiol 63: 2659-2673, 2014.

3. Jukema JW, Ahmed TA, Verschuren JJ and Quax PH: Restenosis after PCI. Part 2: Prevention and therapy. Nat Rev Cardiol 9: 79-90, 2011.

4. Byrne RA, Joner M and Kastrati A: Stent thrombosis and restenosis: What have we learned and where are we going? The Andreas Gruntzig Lecture ESC 2014. Eur Heart J 36: 3320-3331, 2015.

5. Finn AV, Joner M, Nakazawa G, Kolodgie F, Newell J, John MC, Gold HK and Virmani R: Pathological correlates of late drug-eluting stent thrombosis: Strut coverage as a marker of endothelialization. Circulation 115: 2435-2441, 2007.

6. Li X, Chen C, Wei L, Li Q, Niu X, Xu Y, Wang Y and Zhao J: Exosomes derived from endothelial progenitor cells attenuate vascular repair and accelerate reendothelialization by enhancing endothelial function. Cytotherapy 18: 253-262, 2016.

7. Kipshidze N, Ferguson JJ III, Keelan MH Jr, Sahota H, Komorowski R, Shankar LR, Chawla PS, Haudenschild CC, Nikolaychik V and Moses JW: Endoluminal reconstruction of the arterial wall with endothelial cell/glue matrix reduces restenosis in an atherosclerotic rabbit. J Am Coll Cardiol 36: 1396-1403, 2000.

8. Padfield GJ, Newby DE and Mills NL: Understanding the role of endothelial progenitor cells in percutaneous coronary intervention. J Am Coll Cardiol 55: 1553-1565, 2010.

9. Simard T, Jung RG, Motazedian P, Di Santo P, Ramirez FD, Russo JJ, Labinaz A, Yousef A, Anantharam B, Pourdjabbar A and Hibbert B: Progenitor cells for arterial repair: Incremental advancements towards therapeutic reality. Stem Cells Int 2017: 8270498, 2017.

10. Arcangeli A, Lastraioli E, Piccini B, D'Amico M, Lenzi L, Pillozzi S, Calabrese M, Toni S and Arcangeli A: Circulating endothelial progenitor cells in type 1 diabetic patients: Relation with Patients' age and disease duration. Front Endocrinol 8: 278, 2017.

11. Georgescu A, Alexandru N, Constantinescu A, Titorencu I and Popov D: The promise of EPC-based therapies on vascular dysfunction in diabetes. Eur J Oharmacol 669: 1-6, 2011.
12. Gallagher KA, Liu ZJ, Xiao M, Chen H, Goldstein LJ, Buerk DG, Nedeau A, Thom SR and Velazquez OC: Diabetic impairments in NO-mediated endothelial progenitor cell mobilization and homing are reversed by hyperoxia and SDF-1 alpha. J Clin Invest 117: 1249-1259, 2007.

13. Pantin J, Purev E, Tian X, Cook L, Donohue-Jerussi T, Cho E, Reger R, Hsieh M, Khuu H, Calandra G, et al: Effect of high-dose plerixafor on CD34(+) cell mobilization in healthy stem cell donors: Results of a randomized crossover trial. Haematologica 102: 600-609, 2017.

14. Schroeder MA, Rettig MP, Lopez S, Christ S, Fiala M, Eades W, Mir FA, Shao J, McFarland K, Trinkaus K, et al: Mobilization of allogeneic peripheral blood stem cell donors with intravenous plerixafor mobilizes a unique graft. Blood 129: 2680-2692, 2017.

15. Petit I, Jin D and Rafii S: The SDF-1-CXCR4 signaling pathway: A molecular hub modulating neo-angiogenesis. Trends Immunol 28: 299-307, 2007.

16. Yin Y, Zhao X, Fang Y, Yu S, Zhao J, Song M and Huang L: SDF-1alpha involved in mobilization and recruitment of endothelial progenitor cells after arterial injury in mice. Cardiovasc Pathol 19: 218-227, 2010.

17. Anderson EM, Kwee BJ, Lewin SA, Raimondo T, Mehta M and Mooney DJ: Local delivery of VEGF and SDF enhances endothelial progenitor cell recruitment and resultant recovery from ischemia. Tissue Eng Part A 21: 1217-1227, 2015.

18. Li Y, Chang S, Li W, Tang G, Ma Y, Liu Y, Yuan F, Zhang Z, Yang GY and Wang Y: cxcl12-engineered endothelial progenitor cells enhance neurogenesis and angiogenesis after ischemic brain injury in mice. Stem Cell Res Ther 9: 139, 2018.

19. Hoggatt J, Singh P, Tate TA, Chou BK, Datari SR, Fukuda S, Liu L, Kharchenko PV, Schajnovitz A and Baryawno N, et al: Rapid mobilization reveals a highly engraftable hematopoietic stem cell. Cell 172: 191-204.e10, 2018.

20. Tan Y, Li Y, Xiao J, Shao H, Ding C, Arteel GE, Webster KA, Yan J, Yu H and Cai L: A novel CXCR4 antagonist derived from human SDF-1beta enhances angiogenesis in ischaemic mice. Cardiovasc Res 82: 513-521, 2009.

21. Vågesjö E, Öhnstedt E, Mortier A, Lofton H, Huss F, Proost P, Roos S and Phillipson M: Accelerated wound healing in mice by on-site production and delivery of CXCL12 by transformed lactic acid bacteria. Proc Natl Acad Sci USA 115: 1895-1900, 2018.

22. Nishimura Y, Ii M, Qin G, Hamada H, Asai J, Takenaka H, Sekiguchi H, Renault MA, Jujo K, Katoh N, et al: CXCR4 antagonist AMD3100 accelerates impaired wound healing in diabetic mice. J Invest Dermatol 132: 711-720, 2012

23. Zamproni LN, Mundim MV, Porcionatto MA and des Rieux A: Injection of SDF-1 loaded nanoparticles following traumatic brain injury stimulates neural stem cell recruitment. Int J Pharm 519: 323-331, 2017.

24. Fu WL, Xiang Z, Huang FG, Cen SQ, Zhong G, Duan X, Liu M and Leung F: Combination of granulocyte colony-stimulating factor and CXCR4 antagonist AMD3100 for effective harvest of endothelial progenitor cells from peripheral blood and in vitro formation of primitive endothelial networks. Cell Tissue Banking 17: 161-169, 2016.

25. Shepherd RM, Capoccia BJ, Devine SM, Dipersio J, Trinkaus KM, Ingram D and Link DC: Angiogenic cells can be rapidly mobilized and efficiently harvested from the blood following treatment with AMD3100. Blood 108: 3662-3667, 2006.

26. Stewart DA, Smith C, MacFarland R and Calandra G: Pharmacokinetics and pharmacodynamics of plerixafor in patients with non-Hodgkin lymphoma and multiple myeloma. Biol Blood Marrow Transplant 15: 39-46, 2009.

27. Noels H, Zhou B, Tilstam PV, Theelen W, Li X, Pawig L, Schmitz C, Akhtar S, Simsekyilmaz S, Shagdarsuren E, et al: Deficiency of endothelial CXCR4 reduces reendothelialization and enhances neointimal hyperplasia after vascular injury in atherosclerosis-prone mice. Arterioscler Thromb Vasc Biol 34: 1209-1220, 2014

28. Yamaguchi J, Kusano KF, Masuo O, Kawamoto A, Silver M, Murasawa S, Bosch-Marce M, Masuda H, Losordo DW, Isner JM and Asahara T: Stromal cell-derived factor-1 effects on ex vivo expanded endothelial progenitor cell recruitment for ischemic neovascularization. Circulation 107: 1322-1328, 2003.

29. Dai X, Tan Y, Cai S, Xiong X, Wang L, Ye Q, Yan X, Ma K and Cai L: The role of CXCR7 on the adhesion, proliferation and angiogenesis of endothelial progenitor cells. J Cell Mol Med 15: 1299-1309, 2011.

30. Dai X, Yan X, Zeng J, Chen J, Wang Y, Chen J, Li Y, Barati MT, Wintergerst KA, Pan K, et al: Elevating CXCR7 improves angiogenic function of EPCs via Akt/GSK-3beta/Fyn-mediated Nrf2 activation in diabetic limb ischemia. Circ Res 120: e7-e23, 2017. 
31. Yin Y, Huang L, Zhao X, Fang Y, Yu S, Zhao J and Cui B AMD3100 mobilizes endothelial progenitor cells in mice, but inhibits its biological functions by blocking an autocrine/paracrine regulatory loop of stromal cell derived factor-1 in vitro. J Cardiovasc Pharmacol 50: 61-67, 2007.

32. Tarnowski M, Liu R, Wysoczynski M, Ratajczak J, Kucia M and Ratajczak MZ: CXCR7: A new SDF-1-binding receptor in contrast to normal CD34(+) progenitors is functional and is expressed at higher level in human malignant hematopoietic cells. Eur J Haematol 85: 472-483, 2010.

33. Kalatskaya I, Berchiche YA, Gravel S, Limberg BJ, Rosenbaum JS and Heveker N: AMD3100 is a CXCR7 ligand with allosteric agonist properties. Mol Pharmacol 75: 1240-1247, 2009.

34. Narasipura SD, Wojciechowski JC, Charles N, Liesveld JL and King MR: P-Selectin coated microtube for enrichment of CD34+ hematopoietic stem and progenitor cells from human bone marrow. Clin Chem 54: 77-85, 2008.
35. Sun J,Li Y, Graziani GM, Filion L and Allan DS: E-selectin mediated adhesion and migration of endothelial colony forming cells is enhanced by SDF-1alpha/CXCR4. PLoS One 8: e60890, 2013.

36. Vanderslice P, Biediger RJ, Woodside DG, Brown WS, Khounlo S, Warier ND, Gundlach CW IV, Caivano AR, Bornmann WG, Maxwell DS, et al: Small molecule agonist of very late antigen-4 (VLA-4) integrin induces progenitor cell adhesion. J Biol Chem 288: 19414-19428, 2013.

(i) (9) This work is licensed under a Creative Commons Attribution-NonCommercial-NoDerivatives 4.0 International (CC BY-NC-ND 4.0) License. 